\title{
Afinal, o que a organização mundial do comércio tem a ver com a educação superior?
}

Please enlighten me: what does the world trade organization have to do with higher education?

\section{Introdução}

No presente artigo se analisa as implicações jurídicas da liberalização da educação superior para os Membros da Organização Mundial do Comércio (OMC). ${ }^{1}$ A educação, em todos os seus níveis, está inserida como um dos setores de serviços negociáveis dentro do Acordo Geral sobre Comércio de Serviços (Gats), um dos pilares jurídicos da OMC. ${ }^{2}$

Mas em quais circunstâncias a educação superior se tornou abrangida pelo Gats?

Do ponto de vista institucional, a OMC foi criada em 1994 como a "sucessora" do projeto de liberalização comercial que tem suas raízes no General Agreement on Tariffs and Trade (Gatt-1947). ${ }^{3}$ Com o estabelecimento da OMC, ocorreu uma expansão deste projeto. Além do comércio internacional de bens, o comércio internacional de serviços, regido pelo Gats, e temas como propriedade intelectual e investimentos passaram a fazer parte das negociações multilaterais de comércio.

Muito se questiona sobre a inclusão da educação superior neste contexto. Uma crítica freqüente sugere que "educação não é mercadoria e não pode fazer

\footnotetext{
* Doutorando em Direito (S.J.D.) pela Indiana University School of Law. Advogado. Bolsista do programa de doutorado pleno nos Estados Unidos da Capes/FULBRIGHT (gribeiro@indiana.edu)

${ }^{1}$ Este artigo tem como base a dissertação de mestrado desenvolvido pelo autor em 2004, no Centro de Ciências Jurídicas da Universidade Federal de Santa Catarina (UFSC). Eventuais alterações relativas ao texto anterior refletem o contínuo aprendizado sobre o tópico. Erros e omissões são de minha exclusiva responsabilidade.

${ }^{2} \mathrm{O}$ Acordo Geral sobre Comércio de Serviços (AGCS) é normalmente referido na literatura por sua sigla em inglês: General Agreement on Trade in Services (Gats).

3 Tecnicamente, a OMC não sucede o Gatt-1947. O Gatt-1947 é um tratado e a OMC uma organização internacional.
} 
parte da OMC”. Avançamos neste artigo para esclarecermos alguns fatos. Primeiramente, apontar a OMC como o principal veículo de "comercialização da educação" é rejeitar todo um processo que é anterior a sua criação e vem ocorrendo por diversos motivos na esfera interna dos Estados. Por outro lado, analisar de forma crítica as consequiências e o alcance da liberalização da educação superior, bem como de que forma esta liberalização contribui ou não para a "comercialização da educação" é o objetivo deste artigo.

Em um sentido puramente econômico, como destacado pela Comissão formada na Universidade de São Paulo (USP) para a discussão sobre a liberalização da educação como item dos setores de serviços do Gats, a liberalização pode trazer conseqüências positivas e negativas. Dentre as positivas, o aumento de investimentos no setor; a ampliação dos benefícios oferecidos ao consumidor, devido à queda de preços dos serviços em um mercado em concorrência; e atualização tecnológica. Entre as conseqüências negativas, a desnacionalização do setor; o acirramento da competitividade, com prejuízo para os pequenos e médios empreendimentos; e o agravamento do quadro das diferenças regionais, já que a lógica de mercado se expande nas regióes de maior atratividade econômico-financeira. A Comissão destaca ainda que as conseqüências apontadas transcendem o plano meramente econômico e servem apenas de base para outras reflexões. ${ }^{4}$

A opinião da reitora da Universidade Federal de Minas Gerais, Ana Lúcia Almeida Gazzola, sugere outras conseqüências desta inclusão:

Ao arrolar a educação como um item de serviço a ser regulamentado pelo Gatt [Gats], estariam dadas todas as condiçōes para a remoção de quaisquer obstáculos à sua completa mercantilização. Passariam a vigorar para os então chamados serviços educacionais as mesmas normas atinentes aos demais serviços. Equivalência de diplomas, padrões para a formação profissional, validação de títulos estrangeiros e certificação de competências são, entre outros, exemplos do que passaria a obedecer à legislação da $\mathrm{OMC}$, sendo por isto, mantidos fora do alcance de qualquer legislação nacional. De imediato, estará transferida para os interesses comerciais mais vorazes a gestão da educação, afastando o Estado de uma de suas responsabilidades estruturais. A soberania das naçōes na condução de suas políticas educacionais, condição imprescindível para a consolidação e para a garantia de sociedades menos desiguais e mais desenvolvidas, cederá lugar a um mercado voltado exclusivamente para a lucratividade crescente. ${ }^{5}$

São observações relevantes. Como colocado, procuraremos neste artigo enfocar alguns destes aspectos. Em específico, determinar o grau de

\footnotetext{
${ }^{4}$ Comissão do Conselho de Cultura e Extensão da Universidade de São Paulo, Relatório sobre a inclusão do ensino como item dos setores de serviços, no Acordo Geral sobre o Comércio de Serviços negociado no âmbito da Organização Mundial do Comércio. São Paulo: 2003, p. 8.

5 GAZZOLA, Ana Lúcia Almeida. Educação Superior: bem público ou mercadoria? Jornal da Ciência. No 2.030. 10 maio 2002. Veja-se também: ALMEIDA, Paulo Roberto de. Educação no Gats?: Não há motivo para pânico. Jornal da Ciência. No 2.031. 13 mai. 2002.
} 
interferência da OMC na condução da política de educação superior dos Estados e as obrigações a quais eles se submetem em função desta relação.

A parte final deste artigo contextualiza o panorama político da liberalização da educação superior, demonstrando os interesses e conflitos dos Membros no tema.

\section{Comércio de serviços}

A educação superior, como colocado, é tratada como uma modalidade de comércio de serviços no contexto da OMC. Torna-se necessário, portanto, entendermos inicialmente o que se denomina comércio de serviços.

De forma geral, o comércio de serviços traduz a noção de atividades não materializadas e consumidas no momento em que são produzidas. Em uma visão irônica, a revista The Economist sugeriu que serviços "são qualquer coisa vendida que não pode cair nos seus pés". ${ }^{6}$

Como afirma Marconini, Adam Smith talvez tenha sido o primeiro autor a classificar o setor de serviços, embora de forma residual, desprezando sua importância econômica. O trabalho de um empregado doméstico, na visão de Smith, não agregaria nada e valor algum, assim como o valor de algumas classes da sociedade, como os advogados, artistas, palhaços, músicos, etc. Estes serviços não resultariam em qualquer objeto permanente ou mercadoria vendável que durasse depois de executado o trabalho. ${ }^{7}$

Jeremy Rifkin, referindo-se à sociedade norte-americana do início do século $\mathrm{XX}$, descreve o nascimento de uma "indústria" de serviços apontando que os primeiros serviços eram acessórios à produção e à distribuição de bens. À medida que a complexidade das operaçóes de negócio aumentava, os serviços de contabilidade, de planejamento financeiro, de transporte e de comunicação começaram a desempenhar um papel fundamental na produção. Ao mesmo tempo, o surgimento de uma nova classe média impulsionava os gastos de parte das rendas familiares em serviços recreacionais de todos os tipos. Com a entrada da mulher no mercado de trabalho, diversas atividades atribuídas às mulheres no início do século XX, foram também transferidas para o mercado, sendo pagas como serviços. ${ }^{8}$

No plano internacional, a idéia de um conjunto de regras para regular o comércio internacional de serviços remonta à década de 1970 e se relaciona ao interesse de empresas prestadoras de serviços em acessar, principalmente, os mercados de serviços dos países em desenvolvimento, então altamente regulados

\footnotetext{
6 RIFKIN, Jeremy. A era do acesso. São Paulo: Makron Books, 2001, p. 69.

7 MARCONINI, Mário. OMC, acordos regionais e o comércio de serviços: normativa internacional e interesse brasileiro. São Paulo: Aduaneiras, 2003, p. 21.

${ }^{8}$ Rifkin, 2001, p. 68-70.
} 
e controlados pelos Estados. Os países desenvolvidos abrigavam as principais "indústrias" de serviços mundiais, como os aglomerados financeiros e os de telecomunicações, duas das modalidades mais conhecidas deste tipo de comércio em nível internacional.

Quando a OMC foi criada, e o Gats instituído, ainda não estava claro de que forma este conjunto de regras, à regular o comércio internacional de serviços, iria operar. Mais ainda, quais seriam os setores de serviços abrandigos pelo Gats.

Em 1999, o secretariado da OMC adotou uma lista de 12 grandes setores de serviços sujeitos às regras do Gats. Esta lista tem como origem a classificação utilizada pela Divisão de Estatísticas das Nações Unidas e inclui: 1. negócios (como os serviços profissionais jurídicos, de contabilidade e de arquitetura); 2. comunicação (como os serviços postais e de telefonia); 3. construção e serviços de engenharia; 4. distribuição; 5. educação (como a educação superior); 6. meio ambiente (como serviços de saneamento); 7. financeiro; 8. saúde; 9. turismo e viagem; 10. recreação, cultura e esporte; 11. transporte; 12 . serviços de cunho genérico.

Há várias especulações sobre a forma pela qual os 12 setores foram escolhidos para fazerem parte da lista do Gats. Sem dúvida, no caso da educação, houve pressão para sua inclusão na lista por parte dos países desenvolvidos interessados no potencial lucrativo do mercado de serviços educacionais. Este lobby veio principalmente dos Estados Unidos, Austrália e Nova Zelândia, países que historicamente recebem um grande afluxo de estudantes internacionais e têm interesse em acessar os mercados internacionais de educação para suas instituições.

Por outro lado, houve pressão para a retirada da educação da lista. Esta foi a posição adotada, por exemplo, na Conferência Mundial da Educação Superior (CMES) em 1998, realizada em Paris sob os auspícios da Unesco.?

Prevaleceu a inclusão da educação superior na lista do Gats. Como conseqüência, a educação passou a se submeter às regras de não discriminação do Gats, em quatro de suas modalidades descritas a seguir.

\section{Modalidades de comércio de serviços no Gats}

No Gats, o comércio de serviços é definido como a "prestação de serviço" em quatro modalidades, levando-se em conta as particularidades da prestação de serviços no âmbito internacional.

\footnotetext{
9 Panizzi destaca que, concomitantemente à realização da CMES, a OMC se movimentava para incluir a educação no Gats. PANIZZI, Wrana Maria (Org.). Universidade: um lugar fora do poder. Porto Alegre: UFRGS, 2002. A hipótese é confirmada por Dias ao afirmar que "a OMC agia na moita". Ver DIAS, Marco Antonio Rodrigues. Educação superior: bem público ou serviço comercial regulamentado pela OMC? In: PANIZZI, p. 39. Ver também Unesco, Declaração da CMES, 1998, Preâmbulo.
} 
São elas:

1. Transfronteiriço: do território de um Membro ao território de qualquer outro Membro;

2. Consumo realizado no exterior: no território de um Membro aos consumidores de serviços de qualquer outro Membro;

3. Presença comercial: pelo prestador de serviços de um Membro, por intermédio da presença comercial, no território de qualquer outro Membro; e,

4. Presença de pessoas físicas: pelo prestador de serviços de um Membro, por intermédio da presença de pessoas naturais de um Membro no território de qualquer outro Membro. ${ }^{10}$

No caso da educação, os modos de prestação corresponderiam às seguintes modalidades de prestação da educação superior:

1. Transfronteiriço: educação à distância;

2. Consumo realizado no exterior: alunos que se deslocam para estudar no estrangeiro;

3. Presença comercial: provedor de educação que se estabelece, comercialmente, em outro país para prestar serviços mediante sede local, campus-satélite, instituiçôes gêmeas ou acordos de franquia com instituições locais;

4. Presença de pessoas físicas: pessoas que viajam, temporariamente, a outros países para prestar serviços como professores ou pesquisadores. ${ }^{11}$

Para cada uma destas modalidades, o Gats, como um acordo de liberalização comercial, busca prover aos Membros da OMC acesso aos mercados internacionais de serviços por meio da eliminação de "barreiras internacionais" na prestação dos serviços educacionais. Estas barreiras, em cada uma das modalidades podem ser assim identificadas:

1. Transfronteiriço: restrições à transmissão eletrônica de materiais, impossibilidade de reconhecimento ou credenciamento da instituição estrangeira, carga excessiva de impostos ou taxas para a licença ou pagamento de royalties;

2. Consumo realizado no exterior: exigência de visto, exigência de câmbio de moeda, exigência de qualificação prévia de outros países e restrições de trabalho ao estudante estrangeiro;

3. Presença comercial: impossibilidade de obter a licença nacional para reconhecer os diplomas dos estudantes, limitação nos investimentos diretos pelos prestadores de serviço, exigência de nacionalidade,

\footnotetext{
10 Gats, art. I, 2.

${ }^{11}$ Veja-se KNIGHT, Jane. Trade in higher education services: the implications of Gats. The Observatory on borderless higher education. Londres, 2002, p. 5 [http://www.obhe.ac.uk].

12 Knight, 2002, p. 14-15.
} 
monopólios governamentais, elevado grau de subsídio ao prestador nacional;

4. Presença de pessoas físicas: exigências de imigração; requerimentos de nacionalidade, testes, quotas no número de staff temporário, entre outras barreiras. ${ }^{12}$

Nota-se a grande abrangência do Gats nas quatro modalidades de serviços. De fato, o Gats prevê apenas duas exceções a sua abrangência. A primeira exceção são os serviços de tráfego aéreo. A segunda são “... aqueles [serviços] prestados no exercício da autoridade governamental". ${ }^{13}$

Surge, nesse sentido, uma suposta contradição. Se a educação superior pode ser entendida como um serviço prestado no exercício da autoridade governamental, como está ela dentro do escopo da lista do Gats?

Trata-se de uma indagação relevante. No Gats a expressão "serviços prestados no exercício da autoridade governamental" não guarda a eventual correspondência com o conceito de serviços governamentais encontrado, por exemplo, no direito administrativo dos Membros. ${ }^{14} \mathrm{O}$ Gats é um tratado, e, por conseqüência, é interpretado consoante às regras e princípios do direito internacional. ${ }^{15}$ Nesse sentido, a interpretação de "serviços prestados no exercício da autoridade governamental” deve ser esclarecida.

\section{Serviços prestados no exercício da autoridade governamental}

O ponto de partida para analisarmos o significado de "serviços governamentais" no Gats é encontrado no seu próprio texto, quando se estabelece que serviço governamental "significa qualquer serviço que não seja prestado em bases comerciais, nem em competição com um ou mais prestadores de serviços". ${ }^{16}$

A lógica da frase é confusa. A frase traz duas condiçōes negativas conjuntivas para exprimir uma exceção: o que o Gats não abrange. Isso significa dizer que, em princípio, se um serviço não é prestado em bases comerciais, mas "em competição" com um ou mais prestadores de serviços, ele está dentro do escopo do Gats. Da mesma maneira, se não é prestado "em competição", mas em bases comerciais, encontra-se coberto pelo Gats.

Em uma das primeiras comunicações relativas à interpretação de "serviços governamentais"(1998), abrangendo especificamente serviços postais, o Secretariado da OMC afirma que

\footnotetext{
13 Gats, art. I, 3, b: “"services" includes any service in any sector except services supplied in the exercise of governmental authority".

14 Não obstante, observamos que ao longo do artigo será utilizada a expressão "serviços governamentais" como forma de abreviar-se a expressão "serviços prestados no exercício da autoridade governamental".

15 De acordo com as regras de interpretação contidas na Convenção de Viena sobre o Direito dos Tratados (CVDT), descrita a seguir.

16 Gats, art. I, 3, c: "'a service supplied in the exercise of governmental authority' means any service which is supplied neither on a commercial basis, nor in competition with one or more service suppliers."
} 
pode haver também alguma relação entre os serviços postais prestados inteiramente por entidades governamentais e o artigo I do Gats que exclui as funçôes governamentais. Os serviços postais de um Membro, não importa o status do prestador, serão serviços cobertos pelo Gats desde que, e é o que normalmente ocorre, seja prestado em bases comerciais (grifo meu). ${ }^{17}$

Uma comunicação posterior, referente a serviços ambientais, revela que:

um ponto chave [para a exclusão de um serviço como serviço governamental] é se as vendas são feitas em bases comerciais. Mas para começar, não é completamente claro o que o termo "bases comerciais" significa. Entretanto, se os serviços forem considerados como sendo prestados em "bases comerciais", então, independentemente se de propriedade pública ou privada, o setor estaria sujeito as principais obrigações do Gats e a negociação de compromissos dos artigos XVI [acesso a mercados] e XVII [tratamento nacional] (grifo meu). ${ }^{18}$

Mais ainda, em outro documento preparado pelo Secretariado em 2001 como uma resposta às crescentes críticas sobre o Gats pela sociedade civil, afirma-se que:

O Gats cobre todos os serviços com duas exceções - isto é, serviços prestados no exercício da autoridade governamental e, no setor de transporte aéreo, direitos de tráfego aéreo (...). Não obstante seu amplo escopo, o Acordo e as negociações em curso são uma das áreas de menos controversas na OMC. Isto, em função da notória flexibilidade do Acordo, que permite que os Governos, em grande medida, determinem o nível de obrigação que serão assumidas (primeiro grifo original). ${ }^{19}$

Ou seja, nesta última comunicação, o Secretariado da OMC afirma que, independentemente do significado de serviços governamentais e da abrangência do Acordo, o que valeria é a flexibilidade de negociação do Gats. Como veremos, existe decerto flexibilidade no Gats o que, porém, não torna menos controversa a interpretação de serviços governamentais.

De fato, um estudo de 2002 afirma que

é perfeitamente possível que os serviços governamentais coexistam na mesma jurisdição com os serviços privados. No caso dos setores da saúde e educação isto é tão comum, se não é propriamente a regra. Embora não tenha nunca havido uma disputa ou outra ocasião demandando pela interpretação do artigo I:3, parece claro que a existência de serviços de saúde privado, por exemplo, em paralelo com os públicos, não invalida o status do último como serviços governamentais ainda mais pelo seu significado. Este

\footnotetext{
17 OMC, S/C/W/39, 1998, p. 2.

18 OMC, S/C/W/46, 1998, para. 53.

19 OMC, Gats: Facts and Fiction, 2001, p. 6.
} 
dispositivo foi de importância política para todos os Membros na negociação e não há razão em acreditar que eles concordariam em comprometê-lo ou distorcê-lo agora (grifo meu). ${ }^{20}$

Como se vê, a discussão no plano político-institucional da OMC está longe de se encerrar. Uma comunicação de outubro de 2003, do Grupo de Trabalho em Regras do Gats, confirma esta percepção. Quando se discutia sobre em quais modalidades de serviços seriam permitidos subsídios governamentais, a divergência sobre o significado de "serviços governamentais" transparece. Chega-se a propor, inclusive, a criação de uma outra lista contendo o que seriam os serviços governamentais. ${ }^{21}$

Introduzida a problemática sobre a interpretação de "serviços governamentais", fazemos agora uma análise jurídica do significado de "bases comerciais" e "em competição". É necessário enfatizar que buscamos o significado destes termos, de acordo com as regras de interpretação da Convenção de Viena sobre o Direito dos Tratados (CVDT). ${ }^{22}$

Segundo Jackson,

a interpretação jurídica do Gatt e dos Acordos da OMC devem ser consideradas no contexto dos princípios gerais do direito internacional no que tange à interpretação de tratados. Estes princípios gerais são possivelmente melhor resumidos hoje pelo art. 31 da Convenção de Viena sobre o Direito dos Tratados, apesar de tecnicamente esta Convenção não se aplicar em algumas situações, e não se aplicaria em uma controvérsia envolvendo uma nação como os Estados Unidos que ainda não a ratificou. Entretanto, esta porção da Convenção de Viena é considerada por várias nações, incluindo os Estados Unidos, como a codificação de regras gerais de direito internacional costumeiro e, portanto, serve como um texto definitivo que descreve estas regras. ${ }^{23}$

De forma simplificada, como regra geral da CVDT, a interpretação de tratados busca o sentido comum do texto, levando-se em conta seu contexto, objeto e a finalidade do tratado. ${ }^{24}$

20 OMC, 2001, p. 124

21 OMC, S/WPGR/M/44, 2003, para. 43 e 67 (Polônia); Hong Kong (para. 46); Estados Unidos (para. 48); Austrália (para. 52); Coréia (para. 63) e Nova Zelândia (para. 69).

22 A CVDT é fruto dos trabalhos iniciados, em 1947, pela Comissão de Direito Internacional (CDI). Em 1966, a Comissão elaborou um rascunho com 75 artigos que foram a base para a criação da CVDT em duas sessões (1968 e 1969). A CVDT entrou em vigor em 27 de janeiro de 1980 e, em julho de 2006, possuía 106 ratificaçōes.

23 JACKSON, John Howard. The world trading system: law and policy of international economic relations. 2. ed. Cambridge: MIT Press, 1997, p. 120-121.

${ }^{24}$ CVDT, art. 31:"1. Um tratado deve ser interpretado de boa fé segundo o sentido comum atribuível aos termos do tratado em seu contexto e à luz de seu objetivo e finalidade. 2. Para os fins de interpretação de um tratado, o contexto compreenderá, além do texto, seu preâmbulo e anexos:

a) qualquer acordo relativo ao tratado e feito entre todas as partes em conexão com a conclusão do tratado; b) qualquer instrumento estabelecido por uma ou várias partes em conexão com a conclusão do tratado e aceito pelas outras partes como instrumento relativo ao tratado (...) 


\section{Bases comerciais}

O significado de "bases comerciais" se refere, sem dúvida, a comércio, e remete à idéia de lucro. Porém, a interpretação se um serviço é prestado em base comercial ou não pode ser complexa. Por exemplo, pode existir situações híbridas: alguns serviços públicos são prestados pelos Estados sem interesse direto de lucro e, ao mesmo tempo, são prestados por empresas privadas com interesse lucrativo; uma mesma instituição pode prover alguns serviços sem o intuito lucrativo e outros, comercialmente.

Tomemos justamente o caso da educação superior no Brasil. As universidades públicas oferecem o ensino gratuito. ${ }^{25}$ Algumas delas prestam serviços para o mercado privado. Estariam estas universidades operando em bases comerciais segundo o texto do Gats?

Não há ainda uma resposta definitiva. Nas poucas discussões existentes, há um entendimento que, independentemente da natureza jurídica não lucrativa do prestador de serviço (base operacional), o fato do prestador prover qualquer atividade comercialmente (visando lucro) faz com que ele esteja operando em bases comerciais. O termo "bases comerciais" se refere à modalidade de fornecimento e não à "base operacional" do prestador de serviço, de acordo com o sentido comum do texto. ${ }^{26}$

Segundo esta interpretação, dificilmente haverá uma hipótese em que um determinado sistema de educação superior de um Membro seja considerado prestado em bases "não comerciais". Se instituições públicas prestam algum tipo de serviço com o intuito lucrativo, estes serviços governamentais seriam considerados prestados em 'base comercial'.

\section{"Em competição"}

Como a segunda parte do problema, devemos considerar o significado de serviços prestados "nem em competição com um ou mais prestadores de serviços". Observa-se, inicialmente, a imperfeição técnica da tradução oficial de competition como "competição", e não como "concorrência". ${ }^{27}$ Doravante utilizaremos "concorrência" visando tornar mais clara a discussão neste artigo.

O estudo do significado da concorrência adentra o campo de conhecimento do Direito Econômico. Nessa disciplina, a aferição de concorrência pressupõe a delimitação de um mercado relevante. A expressão "mercado relevante" é

\footnotetext{
25 Brasil, Constituição Federal, 1988, art. 206, IV.

26 Esta é a tese defendida por Krajewski. Ver KRAJEWSKI, Markus. Public Services and trade liberalization: mapping the legal framework. Journal of International Economic Law. Vol. 6, no 2, jun. 2003, p. 351-352.

27 Brasil, Decreto-Lei n. ${ }^{\circ} 1.355 / 1994$.
} 
uma tradução literal do inglês (relevant market) e tem justamente o sentido de determinar o mercado pertinente, que interessa, o qual se questiona. ${ }^{28}$

$\mathrm{O}$ mercado relevante pode claramente ser determinado em algumas situações. Por exemplo, no caso da educação superior, quando duas instituições de ensino superior privadas oferecem o mesmo curso em uma mesma cidade ou região. A dificuldade surge, entretanto, quando se indaga se a educação superior privada "concorre" com a pública, para os propósitos do Gats.

Para se aferir concorrência em comércio de serviços, uma analogia com o comércio de bens pode ser feita. No comércio de bens, existe uma distinção entre "produtos similares" e "produtos diretamente concorrentes e substituíveis". ${ }^{29}$

Segundo a jurisprudência da OMC, a noção de produtos que concorrem (in competition) é mais ampla que produtos similares (likeness). Se o mesmo entendimento for aplicado no contexto do Gats, um serviço pode ser considerado "concorrente" ainda que não seja "similar". 30

Knight corrobora esta hipótese. O significado de concorrência é amplo. Os prestadores de serviços públicos estarão em concorrência pelo mero fato de existirem prestadores de serviços privados. Ou seja, mesmo um prestador de serviço de educação pública, que utiliza o tradicional método de aulas expositivas face-a-face com os alunos, é visto como concorrente dos prestadores estrangeiros de educação virtual (e-learning) e com intuito lucrativo (forprofit). ${ }^{31}$

Assim, de forma análoga ao termo "bases comerciais", dificilmente haverá uma situação em que não há "concorrência" em um sistema de educação superior de um Membro. Um relatório da Associação das Universidades e Colégios Canadenses (Aucc) chama a atenção exatamente para esta questão. A mera existência de universidades privadas e com o intuito lucrativo poderiam ser logicamente interpretadas como "em concorrência" com um ou mais prestadores de serviços. ${ }^{32}$

Decerto, do exposto, o escopo do Gats parece não encontrar limites. Poderse-ia indagar se este alcance "universal" do Acordo não ensejaria mesmo a busca de meios suplementares de interpretação já que, em função do artigo 32 da CVDT, tais meios, como os trabalhos preparatórios, podem ser utilizados quando o resultado da interpretação é obscuro ou desarrazoado.

\footnotetext{
${ }^{28}$ FONSECA, João Bosco Leopoldino da. Lei de Proteção da Concorrência: comentários à Legislação antitruste. Rio de Janeiro: Forense, 2001, p. 152-153.

${ }^{29}$ Ver Gatt, art. III, 2 e Anexo I: Notas e disposiçōes suplementares, ad Artigo III, 2.

30 Ver a interpretação de "produtos concorrentes" em Japão - Bebidas Alcoólicas. OMC, WT/DS11/R 1996, para. 6.22- 6.28.

31 Knight, 2002, p. 9.

32 ASSOCIATION OF UNIVERSITIES AND COLLEGES OF CANADA. The Gats and higher education in Canada: an update on Canada's position and implications for Canadian universities, Mai. 2003, p. 10.
} 
Infrutífero, entretanto, seria caminharmos nesse sentido: não há registros públicos dos trabalhos preparatórios do Gats; ${ }^{33}$ ademais, ainda que houvesse, de acordo com Pereira são raros os casos em que os trabalhos preparatórios de um tratado fornecem utilidade à sua interpretação. Nesse aspecto eles foram substituídos com proveito pela prática posterior à conclusão do tratado conforme prescreve o art. 31, \$3, da CVDT..$^{34}$

Deste alcance "universal" do Gats, surgem severas críticas. Segundo Dias, há um sofisma primário na interpretação do artigo I, 3 que é feita no âmbito da OMC:

A OMC faz o que os franceses denominam raccourci, ou seja, toma um atalho, e conclui, através de um sofisma, que, a partir do momento em que se admitem instituições particulares como provedores de ensino, este torna-se comercial [e em concorrência], aplicando-se, pois, a ele as regras da OMC. ${ }^{35}$

Da mesma forma, Krajewski chama a atenção para o caráter econômico do Gats que não leva em conta o aspecto da natureza do serviço. Assim, até mesmo para que serviços governamentais clássicos, como os policiais, sejam considerados fora do escopo do Gats, os mesmos não podem ser prestados nem em bases comerciais nem em concorrência com outros prestadores de serviços. A noção de concorrência, em particular, faz com que, dificilmente, um setor seja excluído do alcance do Gats, per se. ${ }^{36}$

Do exposto, assumimos neste artigo que a educação superior, como um setor de serviços sujeito a liberalização, está dentro do escopo do Gats. Não se trata, absolutamente, de um juízo de valor por parte deste autor. Trata-se de um fato que será ponto de partida para outras reflexões desenvolvidas. ${ }^{37}$

Essa também é percepção de outros autores, mesmo os mais críticos sobre a inclusão da educação superior no Gats. Para Knight, "O Gats existe desde 1995 e não vai desaparecer. (...) A educação é um dos seus setores bases. Isto não será mudado”. Ainda, segundo Dias,

a comunidade acadêmica perdeu a oportunidade de reagir eficazmente, quando, em 1994, foi aprovado o Acordo Geral sobre Comércio e Serviços (...) o debate é

\footnotetext{
33 REYNA, J. The Gatt Uruguay Round: a negotiating history (1986-1992): services. Vol. 2. Deventer: Kluwer Law and Taxation, 1993, p. 2335-2361.

34 PEREIRA, André Gonçalves; QUADROS, Fausto de. Manual de Direito Internacional Público. 3. ed. Lisboa: Almedina, 2002, p. 243.

35 DIAS, 2002, p. 41, 85.

36 Krajewski, 2003, p. 353-354. Segundo ainda o autor, o tão debatido artigo I, 3, 'c' reforça uma concepção neoliberal de serviços públicos que se formava nos anos 1980 e 1990. Idem, p. 359.

37 KNIGHT, Jane. Gats, trade and higher education: where are we? The Observatory on borderless higher education. Londres, 2003, p. 5. [www.obhe.ac.uk]. José Arthur Gianotti afirma, em seu turno, que o "escândalo" é fora de propósito, porque o ensino sempre foi mercadoria desde a gênese da educação formal, na Grécia antiga. Se se adota uma posição "angelical”, acaba-se negociando em condiçōes desvantajosas. Comissão do Conselho de Cultura e Extensão da Universidade de São Paulo, 2003, p. 8.
} 
completamente mal orientado quando se diz que é necessário impedir que o tema da comercialização seja levado à OMC (...). Teoricamente, ainda que isso não seja muito realista, pode-se lutar para que os países retirem da pauta da OMC o tema da educação, ou da saúde, ou do meio ambiente. Mas a proposta terá pouca ou nenhuma possibilidade de ser levada adiante". ${ }^{38}$

Comungamos desta visão. Poderíamos criticar a falta de mandato da OMC para tratar qualquer assunto relativo à educação. Optamos, entretanto, em aprofundar a análise de forma mais realista, medindo os impactos reais do Gats para os Membros da OMC. É o que passamos a desenvolver a seguir.

Focaremos especialmente em duas cláusulas gerais de não-discriminação comercial presentes no Gats: a cláusula da Nação-Mais-Favorecida (NMF) e a cláusula do Tratamento Nacional (TN). Em seguida, analisaremos as disposições do Gats sobre "reconhecimento" de instituições e certificações, pois que guardam relação direta com a questão da educação.

\section{Principais obrigações decorrentes da inclusão da educação superior no Gats: a cláusula da Nação-Mais-Favorecida (NMF)}

Em tratados de liberalização comercial, a cláusula da NMF é um elemento base de não-discriminação entre Estados. A cláusula da NMF obriga os Membros a tratar de forma não discriminatória todos os outros Membros. Por exemplo, no comércio de bens, se o Membro "A" impõe ao Membro "B" uma alíquota de importação "X" para um determinado produto, igual percentual "X" deve ser aplicado ao produto similar importado dos Membros "C", "D", e assim por diante. ${ }^{39}$

No caso do comércio de serviços, a regra é análoga. A cláusula da NMF visa estender os benefícios concedidos ao prestador de serviços de um Membro, aos prestadores de serviços dos demais Membros.

Como regra geral, a cláusula da NMF tem efeitos imediatos. A única forma de um Membro excluir as obrigações decorrentes da cláusula é por meio de exceções anotadas no "Anexo sobre as Isenções ao Artigo II [cláusula da $\mathrm{NMF}]$ ". 40 É o que se denomina uma "lista negativa"; a cláusula da NMF gera plenos efeitos - obrigaçôes para os Membros - a não ser que um Membro "bloqueie" seus efeitos por meio de uma exceção no referido Anexo.

\footnotetext{
38 DIAS, Marco Antonio Rodrigues. Comercialização no ensino superior: é possível manter a idéia de um bem público. Educação e Sociedade. v. 4, n. 84. Campinas: Cedes, set. 2003, p. 819. [http://www.cedes.unicamp.br].

39 Para o comércio de bens, ver Gatt-1994, art. I. No comércio de serviços ver o art. II do Gats.

40 Observe-se a impropriedade técnica do termo "isenções", utilizada na tradução oficial do tratado. Gats, art. II, 2. O termo "exceçôes" traduz melhor o sentido da regra.
} 
E quais seriam estes efeitos no caso da aplicação da cláusula para a educação superior?

Existem poucas análises sobre esta questão. No caso do Canadá, o já mencionado relatório da Aucc, destaca os efeitos da cláusula da NMF no sistema de educação canadense. Naquele contexto, as Províncias canadenses - divisão administrativa interna do Estado canadense - possuem competência para conferir licenças e o status de instituiçōes credenciadas para todos os prestadores de educação. Algumas províncias já permitem que instituiçôes estrangeiras operem em seu território.

A obrigação que surge é justamente a de conceder aos demais Membros os benefícios que algum outro "Membro-mais-favorecido" possui ou venha a possuir. Ou seja, se as instituiçôes de ensino superior de um Membro "A" podem operar no Canadá, todos os outros Membros também o podem, desde que cumpridos os mesmos requisitos exigidos dos prestadores de serviços com origem no Membro "A".

Há, na verdade, um efeito dito "cascata" decorrente da aplicação da cláusula da NMF, pois uma vez obtido o acesso ao mercado de serviços educacionais por um Membro, os demais poderiam dele se beneficiar.

Analisamos a seguir a cláusula do Tratamento Nacional (TN).

Principais obrigações decorrentes da inclusão da educação superior no Gats: a cláusula do Tratamento Nacional (TN)

No comércio de bens, a cláusula do TN significa dispensar ao bem estrangeiro o mesmo tratamento concedido ao bem de origem nacional. Tomemos novamente como exemplo os Membros "A" e "B".

$\mathrm{O}$ Membro " $\mathrm{A}$ " concede tratamento nacional ao produto " $\mathrm{X}$ " importado do Membro "B", se ao produto "X" se aplica tratamento não menos favorável do que aquele concedido ao produto similar "X", de origem nacional. A cláusula tem como intuito prevenir que certas variáveis, como tributação e políticas regulatórias, tornem inócua a queda de barreiras tarifárias negociadas na liberalização de comércio de bens.

No comércio de serviços, a cláusula obriga os Membros a concederem ao serviço (e prestadores de serviços) de qualquer outro Membro, tratamento nacional. Entretanto, é de notar que, pela interpretação literal do dispositivo, a cláusula do TN só tem aplicação para os setores negociados em listas nacionais. ${ }^{41}$ É o que se denomina uma "lista positiva": em relação a um Membro, a cláusula do TN só gera obrigações para os setores "inscritos" em sua lista

\footnotetext{
41 Gats, art. XVII: 1: "Nos setores inscritos em sua lista, e salvo condições e qualificaçôes ali indicadas, cada Membro outorgará aos serviços e prestadores de serviços de qualquer outro Membro ... um tratamento não menos favorável do que aquele que dispensa a seus próprios serviços similares e prestadores de serviços similares" (grifo meu).
} 
nacional de compromissos. ${ }^{42}$ Ademais, uma vez listado positivamente um compromisso, um Membro pode gravar exceções de acesso ao seu mercado.

Ou seja, só há que se falar em amplo TN quando um Membro efetivamente "positive" - assuma compromisso de liberalização para um determinado setor - e não grave nenhum tipo de exceção à cláusula do TN.

$\mathrm{Na}$ hipótese de um Membro liberalizar o setor de educação superior sem gravar restrições de acesso ao seu mercado, ilustramos os principais questionamentos sobre o impacto da cláusula do TN em dois modos de prestação de serviços: modo 3 , presença comercial, e modo 2 , consumo realizado no exterior.

Primeiramente, no modo 3 - presença comercial - pode-se indagar se há conflito entre a obrigação decorrente da cláusula do TN e a política de financiamento educacional (subsídios) de cada Membro. Em outras palavras, de que forma o financiamento público da educação superior é afetado em razão da cláusula do TN.

O relatório da Aucc destaca esta questão no caso do Canadá. Se os negociadores canadenses na OMC assumirem compromissos em sua lista sem nenhum tipo de restrição, o governo canadense, em função da cláusula do $\mathrm{TN}$, poderá não conseguir restringir o acesso dos subsídios somente aos prestadores nacionais. Devido à definição pouco clara de subsídios no Gats, o próprio Secretariado da OMC já havia sugerido que os Membros indicassem como exceção em suas listas que os "subsídios nacionais não estejam disponíveis para os prestadores estrangeiros".

Porém, reforçamos que a interpretação sobre "o fim dos subsídios públicos" na educação superior em função da cláusula do TN é extremada. $\mathrm{O}$ Gats provê mecanismos para anular ou minimizar os efeitos da cláusula do TN.

Quanto ao modo 2 - consumo realizado no exterior - algumas observações devem ser igualmente enumeradas. Esta modalidade abrange a crescente quantidade de estudantes estrangeiros que se deslocam para "consumir" a educação superior no território de outro Membro. Perguntamos: deveriam, nesse caso, os estudantes estrangeiros receber TN em relação aos estudantes nacionais de um Membro? ${ }^{43}$

Embora a questão seja colocada de forma simplificada, pois deveríamos levar em conta, por exemplo, a possibilidade efetiva de se demandar tal direito, alguns Membros, quer por precaução, quer por uma leitura cautelosa das disposições do Gats, gravaram exceções à cláusula do TN. Os Estados Unidos,

\footnotetext{
42 Jackson denomina as negociações de listas negativas de "negociações de baixo-para-cima" (bottom-up approach), em contraposição ao uso de listas positivas denominadas "negociações de cima-para-baixo" (top-down approach). Jackson, 1997, p. 308.

${ }^{43}$ A cláusula do TN, segundo a Aucc, poderia por em risco "restriçôes de 'consumo de subsídios' (isto é, empréstimos a estudantes e bolsas) e subsídios de pesquisa aos cidadãos canadenses e aos imigrantes estabelecidos". Knight, 2003, p. 8.
} 
por exemplo, listam como exceção à cláusula do $\mathrm{TN}$ as bolsas de estudos para o setor de educação. Isto quer dizer que os estudantes estrangeiros "consumindo" o serviço de educação nos EUA (consumo realizado no exterior) não têm direito a uma bolsa de estudos com base na cláusula do TN. ${ }^{44}$

Ressaltemos, em suma, os principais pontos sobre a cláusula do TN: as obrigações decorrentes da cláusula do TN são significativas para os Membros; seus plenos efeitos dependem, contudo, da expressa manifestação soberana do Membro em assumir um compromisso de liberalização para um determinado setor e, igualmente, do grau de restrições que se faça à cláusula do TN.

Analisamos, na seqüência, as obrigações relativas a "reconhecimento" no Gats.

Principais obrigações decorrentes da inclusão da educação superior no Gats: "reconhecimento".

Indagamos agora se a cláusula de "reconhecimento", quando aplicada à educação superior, cria obrigações de reconhecimento de cursos e instituições educacionais, bem como de diplomas estrangeiros para os Membros.

A cláusula de reconhecimento dispõe:

Para efeito do cumprimento, no todo ou em parte, de suas normas e critérios para a autorização, licença ou certificação de prestadores de serviços, e sujeito às disposiçôes do parágrafo 3, um Membro poderá reconhecer a educação ou experiência adquirida, os requisitos cumpridos ou as licenças ou certificados outorgados em um determinado país. Este reconhecimento poderá efetuar-se mediante a harmonização ou de outro modo, poderá basear-se em acordo ou convênio com o país em questão ou poderá ser outorgado de forma autônoma (grifo meu). ${ }^{45}$

O mencionado parágrafo 3, por sua vez, dispõe:

Nenhum Membro outorgará o reconhecimento de maneira que constitua um meio de discriminação entre países na aplicação de suas normas e critérios para a autorização, certificação ou concessão de licenças aos provedores de serviços, ou uma restrição encoberta ao comércio de serviços. ${ }^{46}$

Ademais, o Gats dispõe que todo Membro

(...) concederá oportunidades adequadas aos demais Membros interessados para que negociem sua adesão a tal acordo ou convênio ou para que se negociem com aqueles

\footnotetext{
44 "Scholarships and grants may be limited to U.S. citizens andlor U.S. residents of particular states". Knight, 2003 , p. 8.

45 Gats, art. VII: 1.

46 Gats, art. VII: 3 .
} 
outros comparáveis. Quando um Membro outorgar o reconhecimento de forma autônoma, concederá aos demais Membros oportunidade adequada para que demonstrem que a educação, a experiência, as licenças ou os certificados obtidos em seu território devem ser objeto de reconhecimento. ${ }^{47}$

É necessário atentar para a terminologia utilizada no Gats. O termo "reconhecimento", no Gats, refere-se a "prestadores de serviços" que, por sua vez, "significa qualquer pessoa [física ou jurídica] que presta um serviço. ${ }^{48}$

Isto significa dizer, em tese, que "reconhecimento" se refere à autorização, licença ou certificação de instituições prestadoras de serviços e de profissionais (como advocacia, contabilidade, engenharia e medicina). Assim, tais disposições se relacionam com a educação superior em dois processos distintos e, tradicionalmente, sob forte regulação estatal: o credenciamento de cursos e instituiçõos de ensino superior e a revalidação de diplomas.

No atual estado de negociações do Gats, não é claro qual será a abrangência dada ao texto. Interpretando-o pelo seu sentido comum, o Gats não contém nenhum dispositivo que obrigue determinado Membro a credenciar cursos ou revalidar diplomas de outro Membro. Um Membro "pode" reconhecer, via harmonização de legislação, acordo, convênio, ou mesmo de forma unilateral, determinados títulos de outro Membro, desde que isto não represente uma barreira ao comércio de serviços.

Esta última sentença - contida no parágrafo 3 do artigo VII - representa decerto uma inovação. Com ela, existe a possibilidade de Membros questionarem outro Membro, por meio de processos de consultas e disputas da OMC, se uma legislação interna relativa ao reconhecimento de cursos e diplomas constitui ou não uma barreira ao comércio de serviços. Ou seja, se ela é utilizada de forma discriminatória. Em uma situação extrema, e que parece remota, os órgãos adjudicantes da $\mathrm{OMC}$, em uma eventual disputa, poderiam até mesmo recomendar a modificação das normas de credenciamento ou reconhecimento de Membro, considerando-as discriminatórias ao comércio internacional de serviços educacionais.

Fica a indagação se tal hipótese irá se manifestar na prática, em função de sua sensibilidade. Como colocado, a porta que se abre com o Gats é, no caso de uma disputa entre Membros, a possibilidade de escrutínio, pelos órgãos adjudicantes da OMC, da legislação doméstica dos Membros. Nestas legislações, os Estados tradicionalmente exercem ampla discricionariedade para a garantia de padrões e exigências de qualidade, consoante seus respectivos sistemas de ensino superior.

47 Gats, art. VII, 2.

48 Gats, art. XVIII, 'g' e 'j’ . 
Analisado este último aspecto, apresentamos a posição dos Membros sobre a inclusão da educação superior no Gats.

\section{Posição dos Membros}

Apresentadas as obrigações decorrentes da inclusão da educação superior no Gats, complementaremos este artigo com uma visão acerca da posição dos Membros da OMC sobre o tema.

$\mathrm{O}$ fato de poucos Membros terem assumido compromissos no setor da educação, e menos ainda na educação superior, já reflete, em certa medida, os distintos posicionamentos e a precaução adotada.

Três incertezas contribuem para o baixo grau de compromissos no setor de educação: as incertezas relativas ao escopo e a natureza das obrigações do Gats; o eventual impacto comercial no setor, se assumidos compromissos; e a possibilidade que governos precisem ou queiram adotar políticas futuras que podem resultar inconsistentes com as obrigaçōes do Gats. ${ }^{49}$

É necessário, então, que se proceda à análise das comunicações dos Membros. A primeira delas foi feita pelos EUA ao final de 2000, seguida por comunicações da Nova Zelândia e Austrália. ${ }^{50}$

Quanto ao papel do governo, sem dúvida, as três propostas - EUA, Nova Zelândia e Austrália - convergem ao reconhecer o papel central que os governos desempenham na educação superior. Não obstante, também reconhecem a necessidade da liberalização entre os Membros, buscando destacar benefícios.

A Austrália afirma que o aumento de concorrência traria benefícios gerais aos estudantes, como a queda de preços nas mensalidades; a Nova Zelândia dá ênfase ao intercâmbio cultural e a transferência de tecnologia; os Estados Unidos salientam os benefícios econômicos e sociais da liberalização.

A participação dos setores públicos e privados na educação superior é reconhecida em todas as propostas, embora as reações dos demais Membros nessa discussão variem em função da incerteza do impacto do Gats em seus respectivos sistemas de educação superior.

Quanto aos demais Membros, Israel e Grécia já se manifestaram contra a inclusão da educação superior na $\mathrm{OMC} ;{ }^{51}$ o Canadá teria se comprometido com as associaçôes universitárias, como a Aucc, a tratar o tema com prudência. O Brasil, em 1999, em nota relativa ao comércio de serviços, conclama pelo estabelecimento de regras sobre medidas de salvaguarda, subsídios e

\footnotetext{
49 VANDUZER, Anthony J. Navigating between the poles: unpacking the debate on the implications for development of Gats obligations relating to health and education services. In: PETERSMANN, ErnstUlrich (Coords.). Reforming the world trading system. Oxford: OUP, 2005, p. 192.

50 OMC, S/C/W/55, 1998; S/C/W/93, 2001; S/C/W/110, 2001, respectivamente.

51 Dias, 2002, p. 75.
} 
regulamentação interna, antes dos Membros adotarem novos compromissos de liberalização no setor de serviços. A comunicação brasileira não aborda, especificamente, o tema da educação, em nenhum nível. ${ }^{52}$

Em comunicação de 2002, o Japão reconheceu os benefícios de se promover certo nível de liberalização na educação; porém, sem que se deixe de tomar várias medidas governamentais buscando evitar o chamado "imperialismo cultural". ${ }^{53}$ Tais medidas referem-se, principalmente, à manutenção e melhoria da qualidade do serviço. Nesse sentido, atenção especial deveria ser dada aos consumidores, para que não se vejam prejudicados pela prestação de serviços de má qualidade. O Japão menciona também o risco da proliferação de "fábricas" de diplomas on-line, se os serviços educacionais forem prestados indiscriminadamente além fronteiras. ${ }^{54}$

Assim, EUA, Austrália e Nova Zelândia encabeçam o grupo de Membros defensores da liberalização dos serviços educacionais no âmbito do Gats. Mas em termos reais, como colocado, poucos Membros efetivamente assumiram compromissos de liberalização em seus respectivos setores de educação superior.

\section{Conclusão}

Neste artigo, investigamos a forma pela qual a educação foi incluída na OMC e as obrigaçóes geradas pelas cláusulas do Gats para seus Membros.

Muitas outras perspectivas poderiam enriquecer esta análise. Os pontos aqui destacados, devemos reforçar, refletem uma análise restrita, em um tema de grande sensibilidade. Tal sensibilidade pode ser evidenciada pelos diversos papéis da educação superior na sociedade. Manuel Castells, por exemplo, ao considerar o papel fundamental da ciência e tecnologia como fonte de competitividade na economia da informação, afirma ser a educação superior "o motor do desenvolvimento na nova economia mundial"; 55 sob a perspectiva do indivíduo, o papel da educação superior se revela como forma de capacitação profissional, realização individual e mobilidade social; sem que se pretenda esgotar sua importância, o papel da educação superior se relaciona com a cultura, cidadania e formação da identidade nacional.

De que forma a liberalização pretendida pelo Gats pode afetar os diversos papéis da educação superior, exigem considerações aqui não desenvolvidas. Por outro lado, instigam futuras pesquisas interdisciplinares sobre o tema.

\footnotetext{
52 Dias, 2002, p. 88-89.

$53 \mathrm{OMC}, \mathrm{S} / \mathrm{C} / \mathrm{W} / 137,2002$.

54 Dias, 2002, p. 89-91.

55 CASTELLS, Manuel. The university system: engine of development in the new world economy. In: SALMI, Jamil; VERSPOOR, Adriaan M. Revitalizing higher education. Oxford: IAU, 1994, p. 14.
} 
Sob o viés adotado, chamamos a atenção que o Gats é um tratado multilateral que traz disposições sobre a liberalização progressiva do mercado de serviços em quatro modos de prestação de serviços que possuem relação direta com a educação superior: (1) transfronteiriço, (2) consumo realizado no exterior, (3) presença comercial e (4) presença ou movimento de pessoas naturais.

O Gats exclui de seu escopo os serviços governamentais. Entretanto, um exercício de interpretação de "serviços governamentais", de acordo com as regras CVDT, faz com que o Gats tenha aplicação ampla, pelo mero fato de coexistirem instituições públicas e privadas em um determinado setor. Tal constatação se aplica também à educação superior. Torna-se infrutífero insistir na discussão se a educação superior pode ou não ser incluída no Gats. Ela já está lá e este fato orienta o debate para outras reflexões.

As principais obrigações existentes no Gats decorrem das disposiçōes da cláusula da NMF (artigo II), da cláusula do TN (artigo XVII) e da cláusula de "reconhecimento" (artigo VII). A cláusula da NMF gera efeitos imediatos para todos os Membros da OMC (excluindo-se as exceções gravadas no anexo sobre Isenções ao artigo II); a cláusula do TN, por sua vez, depende dos Membros expressamente assumirem compromissos de liberalização para gerarem efeitos. Uma vez assumidos compromissos, a cláusula do TN permite, ainda, que o TN seja regulado por exceções; a cláusula de reconhecimento, por fim, não obriga os Membros a reconhecerem instituições ou certificações estrangeiras, mas visam impedir que os Membros reconheçam instituições e certificações estrangeiras de um Membro em prejuízo dos outros (de maneira discriminatória).

O grau de interferência, ou ingerência, da OMC na política educacional dos Membros, dependerá, portanto, do grau de liberalização pretendido por cada um dos Membros. Como se viu, na prática poucos Membros adotaram até agora qualquer tipo de compromisso relativo à educação superior, o que reflete uma estratégia de "esperar para ver".

Se não quisermos "esperar para ver", caberá desenvolvermos uma posição sobre o tema. Para isso, o diálogo entre a sociedade, os órgãos responsáveis pela educação superior e aqueles formadores de nossa política externa demanda sintonia. Pode-se se chegar à conclusão que nenhum tipo de liberalização é desejável. Ou mesmo, que certo grau de liberalização traga algum tipo de benefício. Em qualquer um dos casos, o Gats acomoda ambos os posicionamentos.

Recebido em 2 de agosto de 2006 Aprovado em 22 de setembro de 2006 


\section{Resumo}

A educação superior faz parte dos setores de serviços negociáveis no Acordo Geral sobre Comércio de Serviços (Gats), um dos tratados de liberalização existente na Organização Mundial do Comércio (OMC). Neste artigo se busca analisar as conseqüências desta liberalização. Em específico, os impactos jurídicos das obrigações do Gats na conduta das políticas de educação superior de seus Membros. Entende-se que embora o Gats possua a potencialidade de gerar efeitos relevantes, seu modo de operação pode ser utilizado para anular ou minimizar seus efeitos, de acordo com o grau de liberalização pretendido por cada Membro. Por fim, o artigo apresenta um panorama sobre as posições dos Membros, destacando os argumentos pró e contra a liberalização da educação superior.

\section{Abstract}

Higher education is one of the sectors negotiable under the General Agreement on Trade in Services (Gats), one of the World Trade Organization (WTO) agreements. This paper analyzes the consequences of this liberalization. Specifically, it assesses the legal impacts of Gats obligations for the pursuance of higher education policies by WTO Members. The paper argues that despite the potential effects of Gats, the way it works can be used to nullify or mitigate its effects, in accordance with the level of liberalization sought by each Member. At the end, this paper also presents an overview of Members' positions, stressing their arguments pro and against liberalization.

Palavras-chave: OMC, Gats, Gatt, Educação Superior, Liberalização. Key words: WTO, Gats, Gatt, Higher Education, Liberalization. 